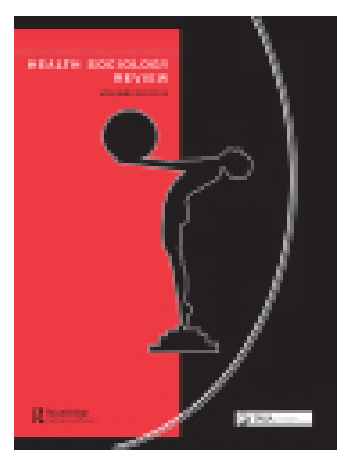

Health Sociology Review

ISSN: 1446-1242 (Print) 1839-3551 (Online) Journal homepage: http://www.tandfonline.com/loi/rhsr20

\title{
'As long as he's coming home to me': vulnerability, jealousy and violence in young people's relationships in remote, rural and regional Australia
}

\section{Kate Senior \& Richard Chenhall}

To cite this article: Kate Senior \& Richard Chenhall (2016): 'As long as he's coming home to me': vulnerability, jealousy and violence in young people's relationships in remote, rural and regional Australia, Health Sociology Review, DOI: 10.1080/14461242.2016.1157697

To link to this article: http://dx.doi.org/10.1080/14461242.2016.1157697

曲 Published online: 21 Mar 2016.

Submit your article to this journal $₫$

Q View related articles ¿

View Crossmark data $₫$ 


\title{
'As long as he's coming home to me': vulnerability, jealousy and violence in young people's relationships in remote, rural and regional Australia
}

\author{
Kate Senior ${ }^{\mathrm{a}}$ and Richard Chenhall ${ }^{\mathrm{b}}$ \\ ${ }^{a}$ School of Health and Society, University of Wollongong, Wollongong, Australia; ${ }^{b}$ Melbourne School of \\ Population and Global Health, University of Melbourne, Melbourne, Australia
}

\begin{abstract}
Drawn from a sample of 88 Indigenous young people in five locations in urban and remote Northern Australia, this research utilised a combination of qualitative approaches to encourage young people to discuss their ideas about sexual relationships and violence. Indigenous youth discussed highly public displays of violence, as well as violence within intimate settings and the interrelationships between these two arenas. A key finding of this research was that young people described violence as an accepted part of their sexual relationships and this normalisation led to significant tensions in their experiences and management of their everyday relationships. While violence around young people's relationships in remote communities was reported to some extent as being controlled through both the public and controlled form they take, we found that the increasing mobility of young people from remote to urban locations due to education opportunities and the impact of social media can lead to more serious forms of violence and tension in the maintenance of young people's sexual relationships. This contributes new findings to the literature on Indigenous young people's experiences in relationship forming and management, an area that has received little attention in the academic literature.
\end{abstract}

\section{ARTICLE HISTORY}

Received 26 April 2015

Accepted 19 February 2016

\section{KEYWORDS}

Sexual violence; fighting; Indigenous youth; Australia

Grant Awarding Body: Australian Research Council.

\section{Introduction}

It's six pm and most people have left the large suburban shopping centre. We hear the thump of fists on bodies and then screaming and sobbing. The fight is between two young girls, but it is brutally one sided; one girl is being held down by a boy while the other girl attacks her. She is dragged by her hair and several other girls take turns to punch her. Other young people surround the scene, filming it on their mobile phones. No-one makes any effort to help the young woman. We hear that 'they were fighting over boys'. The fight ends as several passing adults alert the security guards and call the police. (Senior witnessed event Sept. 2013) 
Drawn from a sample of 88 Indigenous young people in five locations in urban and remote Northern Australia, this research utilised a combination of qualitative approaches to explore young people's ideas about sexual relationships and violence. Our previous research (Chenhall, Davison, Fitz, Pearse, \& Senior, 2013; Senior \& Chenhall, 2008; Senior, Helmer, \& Chenhall, 2014) in both remote and urban settings alerted us to the normalisation of violence in young people's relationships. In this paper we explored how this acceptance of violence can manifest in the experience and management of everyday relationships. We were also interested in exploring a changing dynamic of violence for young people from remote Aboriginal communities. Violence in people's relationships in remote communities may be to some extent controlled through both the public and controlled form they take. In this study, however, we found that the increasing mobility of young people from remote to urban locations to take up educational opportunities alongside the impact of social media has contributed to different forms of violence and tension featuring in the maintenance of young people's sexual relationships. This contributes new findings to the literature on Indigenous young people's experiences in relationship forming and management, an area that has received little attention in the academic literature. This research is based on findings of the research project 'Our Lives Study: Culture, Context and Risk' a three-year Australian Research Council Linkage study, which examined young people's sexual health experiences.

\section{Intimate violence in aboriginal cultures and communities}

As our study explored the experiences and understandings of sexual violence among Indigenous young people from urban and remote communities, it is important to review two bodies of literature in the exploration of our material. The first includes qualitative studies of young people's contemporary understandings of intimate violence and related factors, such as gender roles. While this body of work is not specifically related to Aboriginal populations, it has relevance to this study as young Indigenous people are becoming increasingly drawn into globalised youth cultures. Gender roles are further influenced by media messages about the sexualisation of young people, and offer opportunities for both Indigenous and non-Indigenous young people to incorporate these into their lives and relationships (Renold \& Ringrose, 2011). The second body of literature is largely ethnographic and explores cultural understandings and experiences of violence in Aboriginal communities as well as the influence of alcohol abuse, social fragmentation and poverty.

\section{Intimate violence in young people's relationships}

Violence in young peoples' relationships is often described as dating violence (see for example, Lavoie, Robitaille, \& Herbert, 2000; Wekerle \& Wolfe, 1999) or partner abuse (Barter, 2009) and focuses on violence within intimate relationships. However, others such as Powell $(2007,2010)$ in her exploration of young people's understandings of gender-based violence, argue there are no clear categories of violence. Kelly (1987, p. 54) has suggested that violence can be seen as a continuum from 'choice to pressure to coercion to force'. Within this continuum, it may be difficult for young women to understand how to define their own experiences, especially if some degree or presence of violence is expected and tolerated. Although various forms of violence in young people's relationships appear to 
be common (ABS, 2012; Powell, 2007; Scott, Steward-Streng, Manlove, Schelar, \& Cui, 2011), little is known about how young people experience and understand violence, how they interpret the motivations for violence, and what effect violence has on identity, sense of self and future relationships (Jackson \& Cram, 2003, p. 24).

Chung (2005) has argued that the lack of knowledge about young people's experience of violence is due to a predominance of psychological and survey methods in research exploring violence in young people's relationships and the reliance on attachment theory and social learning theory to explain it. These theories, she has argued, which explain relationship behaviours in terms of early childhood environmental influences and caregiver attachments, are inadequate for appreciating in any in-depth sense of how young people understand and experience violence, or the structural causes of violence. Chung (2005, p. 466) has stated that 'both explanations pay little attention to power differences related to age, gender, sexuality, abilities, culture or class'.

Instead, Chung and others (such as Lees, 1993 and Tolman, 2002) have directed their research towards exploring the influence of gendered scripts for behaviour in heterosexual relationships from the perspective of young women. In Chung's (2005, p. 450) interviews with young women, she found masculine dominance in relationships to be pervasive, but there was also reluctance on the part of young women to acknowledge their lack of power. The consequences of young women's beliefs in equality and personal choice, underpinned by ideas of romantic love, made them both vulnerable to violence and reluctant to admit to violence due to feelings of shame at having made poor choices and becoming a victim (Chung, 2005, p. 542).

\section{Cultural understandings of violence}

The ethnographic literature suggests that fighting practices play an important role in the lives of Aboriginal people and that aggression may be viewed as an expected, sanctioned and highly rule governed way to resolve disputes (Hiatt, 1965; Langton, 1994; Macdonald, 1994; Warner, 1958). In remote communities, previous studies have reported that physical violence has been used to punish people for breaking traditional laws or sanctions (Bell, 1983), as a result of sexual jealousy (Bell, 1983; Burbank, 1994; Goodale, 1971) and a perceived failure to comply with expected gender roles in a relationship.

In previous research, Senior and Chenhall found that young women from River Town talked about violence between men and women as an expected component of a relationship $(2008,2012)$. Although women stated that they would not tolerate violence as a result of drinking, drug abuse or bad temper, they did describe situations where male violence against women was accepted as appropriate behaviour. Women suggested that in some circumstances, such as when a wife was viewed as being 'lazy' or 'unfaithful', it was acceptable for a husband to hit his wife to punish her for her wrongdoing. This perspective was viewed as being reinforced through traditionally sanctioned forms of violence that a man may inflict upon a woman. In previous research, conducted by Senior (2003), older women discussed the respect that a woman must have for her brothers and uncles. She may not walk in front of them, she must hide all evidence of her bodily functions from them and she must not swear at them or be sworn at in their presence (see also Burbank, 1994, p. 78).

By far the most extensive study of the role of aggression in an Aboriginal community is Burbank's Fighting Women (1994). In her detailed exploration of the role of 
aggression in everyday life, Burbank argued that feelings of anger in this community were equated with acts of aggression, unlike contemporary Western society where 'one feels anger but then may act aggressively or not' (Burbank, 1994, p. 57). Aggressive acts were commonplace between young people, between women and between women and men. Because aggression was viewed as an acceptable way of solving disputes, a series of rules and sanctions existed that served to protect people from being seriously injured. The first was that fighting be conducted in a public place, where on-lookers could intervene if rules were broken (for example, attacking the head rather than the arms and legs). The second was that a persons' family was usually able to provide support and an alternative place to live if needed. In addition, Burbank argued that women's fighting provided them with important experiences in dealing with the anger of men, training them to 'think of themselves as fighters, an identity that serves them well when their opponents are not other women, but men' (Burbank, 1994, p. 122). Sexual jealousy was also noted as a key motivating factor in the initiation of women's fights, with young girls fighting over boys and married women fighting over another women's attempt to steal their husband (Burbank, 1994; see Senior \& Chenhall, 2012).

\section{Indigenous violence in a globalised world}

As discussed above, although some forms of violence were either expected or tolerated, other forms, such as violence motivated by alcohol abuse were not. In her review of violence in Northern Territory Aboriginal communities, Bolger addresses three factors that change the face of intimate violence: alcohol abuse, large communities where surveillance of individual women becomes a problem and problems associated with 'cultural breakdown, dislocation, alienation and poverty' (Bolger, 1991, p. 44).

In Australian Indigenous communities, the Northern Territory Intervention (2008) identified pornography as a key contributor to sexual abuse of children and violence in relationships and pornography was banned from Indigenous communities along with alcohol. Rasmussen (2015) has argued that the signs that were erected outside every community prohibiting pornography and alcohol became a very public form of sex education and an enduring source of shame to the people who had to live behind them. As Merskin (2011) points out, however, such initiatives do not address the problem of a society where pornography has become increasingly mainstream and pornographic images and concepts abound in magazines and pop culture. Seemingly innocuous material has been found to convey confusing and possibly dangerous messages to young people about gendered roles and acceptable behaviours within relationships. At the same time as the Northern Territory Intervention, pornography and fetishised violence was becoming increasingly mainstream in Australia and around the world, with an increasing number of Australian magazine articles aimed at young women providing advice about how to 'porn up your sex life' and songs with highly suggestive lyrics that eroticized the submission of women to men's desires (Renold \& Ringrose, 2011). Given this context, the questions guiding the analysis of our material are: How do Indigenous young people negotiate the multitude of influences (from traditional through to the effects of a globalised youth culture) affecting their understanding of relationships, gender roles and violence, and how is this enacted in their everyday lives? 


\section{The 'Our Lives' project}

The primary aim of the 'Our Lives: Culture, Context and Risk' project (a three year Linkage grant funded by the Australian Research Council) was to investigate sexual behaviour and sexual decision making in the context of the everyday life experience and aspirations of Indigenous young people aged 16-25 in the Northern Territory, Western Australia and South Australia. Ethics approvals for this research was granted through the Northern Territory Department of Health and Menzies School of Health Research (HREC-2010-1426), the Western Australia Aboriginal Ethics Committee (HREC-36410/11), and the South Australia Human Research Ethics Committee (HREC/12/SAH/11).

\section{Participants}

This paper presents results from 88 Indigenous young people who participated in the Our Lives project from urban and remote areas in the Northern Territory, Western Australia and South Australia. We worked closely in conducting the research with groups of young people who were engaged with specialist services for young people (including groups for young mothers) and in community-based settings. All participants were attending or had previously attended Australian government or private schools and had a competent level of English and either spoke standard Australian English or Australian Aboriginal English (Vinson, 2008).

\section{Methods}

This research employed a range of qualitative methods building upon extensive prior ethnographic research in one remote Aboriginal community (Senior, 2003). In this project, we conducted a series of workshops and interviews with young people, utilising a range of approaches to guide group discussions, including scenario-based body mapping and participatory community mapping. In the body mapping exercise, groups of 5-8 young people worked together to decorate a life-sized body in response to a fictional scenario about characters sexual experience and decisions (see Chenhall et al., 2013 for full description). In the participatory community mapping exercise, young people were asked to draw their community, their movements around the community, where they liked to 'hang out' and where they felt safe and unsafe (see also Power, Langhaug, \& Cowan, 2007). Individual interviews were conducted with a smaller group of young people (20) to follow up on key themes found during the workshops. The use of visual methodologies aimed to encourage young people to feel safe and open to discussing aspects of relationships that often remain hidden, revealing the complexities of different contexts in understanding sexual relationships and violence.

\section{Results}

\section{'You think they are your world, maybe' - relationships, romantic love and violence}

The first major finding of this research is that young women placed emphasis on the importance of managing relationship in their lives, arguing that they had few other 
opportunities in their lives to compete, demonstrate success and win admiration from their peers (see also Senior \& Chenhall, 2008, p. 278). Efforts to 'hold on to their boyfriends' were described as requiring careful planning, cooperation and determination, but also had the result that once achieved, girls would thereafter accept and tolerate some forms of violence within their relationships. All the young women talked about the difficulty in leaving relationships due to their high level of emotional investment:

My thoughts are ... you get to that stage and you've had enough and you don't want to be at the same time with that person. You don't know how to leave, you love them too much (girls agree). You think they are your world maybe. (Indigenous female, Western Australian town)

They were also aware, however, that the young men in their relationships had considerably more power to have sex with other people, especially when the young woman was pregnant or had children to care for:

Most girls stay with their baby's daddy, but in the long run, the boy ends up cheating. They say (the boys) 'I'm going out with my friends, you stay home with bubba'. They say 'I'm only with you, I love you, but you know they are out cheating'. (group interview Indigenous females, Western Australian town)

Those boys are like the Devil, they'll force you, sometimes they bash their girl if the girl won't let them. They go and cheat on their girl, if they don't like you, because you don't open your legs. (Group interview Indigenous females, Northern Territory remote community)

All the boys are like that. When their girlfriend is pregnant they won't have sex with her they want someone else. They couldn't even wait two weeks to have sex. (Group interview Indigenous females, Northern Territory remote community)

The young women also discussed the impossibility of negotiating or even consenting to having sex when men had been drinking in their communities.

Yes. Lots of girls are getting pregnant, lots of fifteen and sixteen year olds. I think fourteen is the youngest one .... You can't stop it when those men are drunk they get horny and want to fuck any girl they see. They do a lot of forcing things, that's sexual abuse. (Individual interview Indigenous female, Northern Territory remote community)

Although young women spent considerable time investing in their relationships, the interviews demonstrated that they also experienced feelings of resistance to the norm of being in and staying in an intimate relationship. When taking an outsider perspective, and reflecting on relationships, these participants were able to describe what they viewed as gendered inequalities and the problems created by gendered scripts for behaviour. They had less confidence, however, in their ability to resist such norms when they are within such a relationship.

\section{Behind closed doors violence}

Young people were encouraged to select the scenarios in the body mapping exercise that interested them, and there was one scenario which was particularly appealing to Indigenous females living in urban settings. This scenario dealt specifically with violence within intimate relationships and told the story of the fictional characters George and Tanya who had been living together. George was described as 'drinking a lot and sometimes hits Tanya'. The story focused on George's desire for sex after a drinking session and 
Tanya feeling sick and not wanting to have sex. Tanya already has one baby and thinks she may be pregnant again.

Throughout the discussions about this scenario, the young women agreed that Tanya would risk her well-being, her security and her relationship if she refused to have sex with George:

He will beat her up, he will probably be pissed off because he wants to have sex, she is his woman. Depending on how drunk he was he might rape her, and especially because she is his wife, some men have that mentality, 'its my wife, I can do what I want'. I mean, it might not be like really horrible violent rape, she might say, 'no, no, no' and just lie there and just take it. So she wouldn't even think it was rape, I guess, she will be just like 'he is my partner'. I think she will feel like shit, but I don't think she will be like 'he raped me'. She will be like 'I did not want it but it happened' (young women agree). (Body mapping workshop Indigenous females, Northern Territory urban centre)

The language in this quote is important. The young women describe George as believing the woman (Tanya) is his possession: 'It's my wife, I can do what I want'. The perception that they also see women as the property of their husbands is stated in the first line: 'She is his woman'. Although the young women agrees that forcing Tanya to have sex is rape, they again lessen the impact, 'it might not be really horrible rape' and tell a story of just putting up with it, to satisfy George. This emphasises the difficulties noted by Powell (2010) and Kelly (1987) for some young women in distinguishing and naming violence in their relationships. In this case, the young women have clearly defined the problem: George has the potential to rape Tanya if she does not acquiesce to his desires. A tension arises, however, regarding a reluctance to define these experiences as a form of violence that is so unacceptable that leaving the relationship is viewed the best course of action.

In the discussions around this scenario, the young women put forward a discourse of responsibility as a reason to stay with George. They also provided defended the primacy of the 'romantic' relationship over other priorities or concerns (see also Chung, 2005). Because of the importance of being in an intimate relationship, the violence itself was described as an impediment to attempt to overlook. The girls also insisted that George's actions should be understood as a result of his drinking, not as a flaw in his behaviour:

Trapped yeah! You want the baby, you want to keep the man, you might love him, but it (the violence) is the one thing that is getting in the way, you just over look it

Q: Would she stay?

Especially with the kid. Umm Hmm, that might just cement it, George is really nice to her when she is sober you know. (Body mapping workshop, Indigenous females, Northern Territory urban centre)

These participants also described a fear of the consequences of talking to their partner directly about his aggressive behaviour:

If she thinks she can handle it, she might just brush it off. Or if he is like really beating her, she might ask a close cousin or close sister, someone definitely close who is not gonna tell husband or something like that. (Group interview, Indigenous females, Northern Territory urban centre)

In this account, the young women talked about being able to 'handle it' and 'brush it off, again reinforcing the notion that they were prepared to tolerate a level of violence. 
It was only if he was 'really beating her' that she might seek help. Other young women talked about the shame that the young woman might feel by admitting that she had made wrong choices in her relationship and that there would really 'be no one that she could talk to'. Young women's vulnerability in relationships was demonstrated in their perception that if Tanya did not have sex with George that he would simply go out and find someone else to have sex with.

He'll probably be humbugging her for it. If she says she is sick he'll most probably go back to the pub and get drunk and see someone else. Or he would probably force her. (Body mapping workshop, Indigenous females, Western Australian town)

When women were asked if they would be comfortable talking about domestic violence with their friends and family or asking for help, their responses were usually negative. When reflecting on the George and Tanya scenario, they explained that the young woman would be more concerned to protect her relationship and support George's dominant position. The women positioned Tanya as being in the wrong, by demonstrating insufficient loyalty to her partner and 'betraying him'.

When it is your husband you have a loyalty towards him, so she will try and hide it, she will feel as if she is betraying him if she does otherwise. (Body mapping workshop, Indigenous females, Northern Territory urban centre)

One group of Indigenous young men commented that it was possible for them to feel vulnerable in relationships, but that violence perpetrated by females on males was rarely acknowledged or reported:

Girls get abusive too. It happens more than you think, girls use anything; sharp bottles, knives and their nails. He probably wouldn't fight back because he wouldn't feel it was right to hit a girl. He wouldn't tell anyone because he'd be too ashamed. He wouldn't be believed. (Body mapping workshop, Indigenous males, Western Australian town)

What is interesting in this example (from a regional urban community) is that the boys viewed violence perpetrated by female partners as a rare and shameful event and assumed they would not be believed if they spoke about it. The men's example, as with the previous female examples, reveal a changing understanding of violence, from something that is out in the community, under constant surveillance and an acceptable way to deal with grievances, to something that is an individual experience, hidden and shameful: behind closed doors.

\section{'Boys are the boss': gendered explanations of violence}

Young women talked about the stark choices that they sometimes made when choosing to pursue employment. They considered that they could either have a boyfriend and children or have a job; it was not possible to have both at once. This could be related to their expectations and experience of vulnerability in relationships:

Ada: $\quad$ You have to stay single if you want to work. Boyfriend may bash you from jealousy.

Sally: $\quad$ Boys are really jealous (all the other girls agree), they won't let you have a job, too jealous of the people you are working with. 
Margaret: Some girls want to go to work, but the boys pull them out of work, they don't want them to be with other people. (Group interview Indigenous females, Northern Territory urban centre)

Given the social prestige that young women achieved by maintaining a relationship and the importance of having children, it is hardly surprising that for many young women, putting these at risk is too high a price to pay for the chance of engaging in employment. In the following discussion, the jealousy expressed by young men was interpreted as evidence of that women working is viewed as threat to masculine dominance in relationships:

If a girl's boyfriend knows she has been going with other boys, he'll turn around and bash her, hit her and start swearing at her. Boys think they are better than girls. Boys are really jealous (others in the group agree). They won't let you have a job, too jealous of the people you are working with. Boys get really jealous of their girlfriend. Boys are still telling girls what to do ... Boys are the boss. (Group interview, Indigenous female, Northern Territory urban centre)

The young men in the community also described jealousy was a major problem in their relationships, and talked about feelings of frustration and confusion about how to manage this issue:

Jealousy is a big problem here, one of the worst communities for jealousy. Young boys get it into their heads that even a one-night stand with a girl means you are together, even if she doesn't want it to be any more than one night. It's even worse if they are right skin. The boys get angry and beat the girl sometimes with sticks. Many times this leads to others getting involved and the whole thing gets out of control. (Individual interview, Indigenous male, Northern Territory urban centre)

The men's accounts of the problem of jealousy focused on relationships - 'a one night stand with a girl means you are together' - but also on issues of entitlement arising if their partner is the 'right skin', i.e. an appropriate marriage partner as prescribed by the Aboriginal kinship system. The young men did not talk about the underlying causes of jealousy as perceived by the young women, in terms of their desire to control the lives of their partners.

However, the young men did attempt to develop a rationale for believing that young girls may 'deserve to be bashed' if she has provoking her male partner through her choice of clothes:

Jealousy is really bad, but what girls have got to remember is that sometimes when they get hit, they ask for it by dressing like a slut. (Group interview, Indigenous males, Northern Territory urban centre)

This notion of 'dressing like a slut' did not, however, according to the young men interviewed in this project, include any attention to personal appearance, including shaving one's legs, plucking eyebrows and wearing coordinating clothes (see also Senior \& Chenhall, 2008). Young women reported that such personal grooming was highly admired, but only safe and achievable for young women who did not have a boyfriend.

In their second attempt to explain the causes of violent behaviours, the young men discussed instances of girls deliberately flirting with other men to provoke their anger. The young men described feeling forced to prove to all on-lookers that they cared through 
the demonstration of his physical anger, thus suggesting that they were being pushed into being violent, rather than having any agency over that behaviour:

Sometimes those girls will tease another fella, so that their man will hit them, just to show everyone that he cares and that she's with him. (Group interview, Indigenous males, Northern Territory urban centre)

Fear of jealous reprisals due to 'being found out' for having had sex with another partner contributed to young people's reluctance to attend sexual health clinics, where they feared a lack of confidentiality:

Young people don't go to the clinic, they are too scared, embarrassed about privacy and secret things. Worried about gossip. The story will go out to one of the girls' friends and they will know she has some sickness. That story is not from the nurses, but from others waiting in the clinic. They see a young person go in and they know what they are in for. And if that girl's boyfriend knows that she has been going with other boys, he'll turn around and bash her and hit her and start swearing at her. (Individual interview, Indigenous females, Northern Territory urban centre)

\section{Public fighting and the role of social media}

In contrast to young men's expressions of jealousy, which focused on private retaliation, young women's expressions of jealousy largely played out in the public area and targeted other girls, accused of 'stealing a boyfriend', rather than the boyfriend himself.

If Dylan is seeing another girl too and that other girl finds out she'll get violent and angry.

(Group interview, Indigenous females, Western Australian town)

Fights were described by young women as being enacted in the public arena with the location selected to ensure visibility, offering a degree of surveillance and protection (see also Langton, 1994 and Burbank, 1994). Young women explained that fights were often recorded by onlookers with their mobile phones and later uploaded to websites, such as Youtube, making the content available to a much broader audience. For example, the most recent fight witnessed in a remote community during the research for this project occurred in the street outside a supermarket, the busiest street in town. Although these fights appeared to be an acceptable way of resolving a conflict, with few lasting consequences, the advent of mobile phones with cameras has added a new dimension. Rather than being a transient event, the posting of fight videos on YouTube has the potential to prolong the outcomes of the fight (both the victory of winning and the shame of losing) to potentially hundreds of people for an indefinite period. During our research we were alerted by young people to numerous examples of young people posting such events to YouTube. Furthermore, throughout out fieldwork we observed that the movement of young people from remote communities to urban centres to attend school has meant that behaviours, such as public fights, are increasingly being transferred from a remote to an urban context. But in doing so, the usual sanctions and safety nets are removed; the fights are not monitored by the community and the young person's family are unlikely to be able to step in and assist them.

In young people's accounts of their environments, the public places where young people fight were highlighted as both places of danger and places holding a high degree of fascination: 
They just hang around there (pointing to the area on the risk map), that's the unsafe place, that's where all the violence happens, but everybody hangs out here in the streets. (Community mapping workshop, Indigenous females, Western Australian town)

Young people warned that people have to be careful in such environments not to provoke the jealousy of another person:

Girls bash you if you look at them the wrong way or if you look at their boyfriend. (Community mapping workshop, Indigenous females, Northern Territory town)

Again the use of social media is pertinent here and used not only to document the end point of jealousy in relationships, but also to engender fighting:

Most fighting occurs between sixteen year olds fighting over grog and relationships. The biggest fights come from social media sites like Facebook. People often talk about each other on Facebook, they also talk about who slept with who and they often rate sexual partners on the Divas chat site. (Group interview, Indigenous females, Western Australian town)

\section{Discussion}

Our results suggest that violence was both frequent and expected in the relationships reported by the young people who took part in our research. Although these young people were familiar with intimate violence, it was also clear that violence was often perpetuated in a much wider and public sphere also. Public fights, which were then filmed and posted on YouTube, were an expected female response if a young woman was suspected of 'stealing' another woman's partner. Such events became major sources of entertainment for young people, with large groups gathering around the fights and even larger numbers viewing them through social media. We found that the increasing opportunities for young people to move away from their communities to attend school, increases the risk associated with this behaviour. This appears to be because fights are enacted in a context where community surveillance is unlikely, and where families are not around to help out when needed. This research has identified the different types of violence in private and public spaces and the linkages between these with the increasing use of social media.

A further finding of this research is that young women and men provide very different gendered explanations for violence in relationships. The aggression which characterised young women's efforts to secure their relationships within the public gaze (see also Senior \& Chenhall, 2008) contrasts strongly with their accounts of vulnerability and submissiveness within their relationships, where they talked about 'putting up with it' or 'giving in'. Both approaches, however, were influenced by the prestige of maintaining a relationship ('holding on to a boy') and the dominance of male power within relationships. Young men and women discussed men's violence, with young women explaining that jealousy and misunderstanding about the status of a relationship is a source of men's violence. In contrast, young men stated that they often felt forced into committing acts of violence towards women because of social expectations concerning expressions of anger following perceptions that young women were acting or dressing in ways that made them sexually available to others.

Intimate relationships for young women were characterised by their lack of autonomy and a perception that boyfriends would move on to another partner if given sufficient 
opportunity or reason, such as a young woman not wanting or not being able to have sex with him. This resonates with other studies of youth sexuality, where fear of a partner moving on is a key reason for engaging in unwanted sex (Powell, 2010). Young women who provoked their partner's jealousy knew that they were at risk of violence. They also knew, however, that it was very easy to behave in ways that could be interpreted as being sexually provocative, including paying any kind of attention to one's appearance, having a job or talking to (and being perceived therefore as flirting with) another man. It was therefore difficult to protect themselves from the risk of violence. Young men worked hard to explain that although they were frustrated by feelings of jealousy, they could also feel that they were manipulated or forced by women into being physically violent. Such views serve to reinforce the dominance of young men in relationships, where even the beaten young women would invest in narratives that argued the young man was only acting to 'protect the relationship'.

Various studies have described young people's acceptance and tolerance of domestic violence in non-Indigenous settings (Dublin's Women's Aid, 1999; Kenway \& Fitzclarence, 1997; Rosen, 2004). For example, McCarry (2007, p. 342), on the basis of interviews with high school students, argued that young people validate male violence on the basis of their perceived greater power and authority within relationships and consider violence to be part of a normative male gender role. Similarly in this study, Indigenous young women's stories of being trapped within a violent relationship emphasised their vulnerability. Their emotional investment in relationships was significant and they talked about 'putting up' with a level of violence to protect and maintain their relationship. Rosen (2004), in a study of low income teenage mothers, reported that young women who pursued relationships against the advice of their family and friends were left with limited support when they did not work out. Furthermore, some young women may be reluctant to accept that violence is 'really bad' due to a fear of being seen as weak or unable to cope with difficult circumstances (Chung, 2005). Young women may therefore be invested in remaining in a romantic relationship because it can provide both an identity (as a partner and as a mother) and financial security.

Throughout the narratives presented in this research, young men and women appeared to be following a fairly conventional gendered script for normative behaviour in relationships. Young women engaging in public aggression and private submissiveness are doing what they believe is appropriate to 'hold on to their boyfriends', who are described by both groups as the dominant partners in relationships. Traditional gender scripts 'which suppose that boys initiate and vigorously pursue sexual involvement irrespective of their partner's wishes' (Barter, 2009, p. 224), reinforce the notion that sexual coercion and violence are normal and expected within relationships.

In Burbank's (1994) study, she argued that the equation of anger to aggression, led to regular violent episodes in the community and that an important consequence of this was that violence was neither taboo nor strange and women knew how to protect themselves. Burbank contrasted this with non-Indigenous culture where violence may be regarded as anomalous to the female sex role, and hidden behind closed doors. In this study, examples of both kinds of violence were apparent, and were motivated by both relationship norms and jealousy, but with very different outcomes. The first is the perpetuation of public fighting, an event in which women participate on a regular basis. The second is the non-public, intimate form of relationship violence, in regard to which some young women may be 
heavily invested in notions of the importance of romantic love and the perpetuation of male dominance. Although the first context for relationship violence is certainly confronting for non-Indigenous outsiders to view, the woman may actually be far more vulnerable in the second. Young women in the urban communities also talked about a woman being the possession of a man using expressions such as 'she's his woman', but instead of resisting this definition, their narratives tended to reinforce it or embrace it as being a desirable situation. Such statements need be interpreted as revealing of the significance of romantic love for these young women, and the importance of sustaining a relationship at whatever personal cost. A key finding of this paper, therefore, is that while young womens' descriptions of violence followed cultural explanations about sanctioned violence and promoted male dominance, young women - at least in some contexts - also understood that these explanations were unjust and disempowering.

\section{Conclusion}

This paper has explored violence in relationships from the perspective of young Indigenous people from urban, rural and remote communities and contrasted the public displays of aggression often initiated by young women to protect their relationships with their submissive behaviour within their relationships. The tensions between public and private, and the assumed normative gender roles within these settings mean that the usual classifications of domestic violence are insufficient to completely describe the experience of violence for the young people in this study.

Our work contributes to the literature on the sexual behaviour of Indigenous youth and the factors that contribute to risk taking in relationships. It provides a window into how young people understand and negotiate violence in relationships. This research is unique as we worked directly with young people in communities using visual methodologies that allowed young people to address uncomfortable subjects through fictional scenarios and drawing. By using these methods we were able to draw out a complex story about young people's views and beliefs about relationships and normative behaviours within these relationships, which are often subjects that remain hidden behind closed doors.

\section{Disclosure statement}

No potential conflict of interest was reported by the authors.

\section{Funding}

This work was financially supported by Australian Research Council.

\section{References}

Australian Bureau of Statistics. (2012). Personal safety Australia. Canberra: Commonwealth Government of Australia.

Barter, C. (2009). In the name of love: Partner abuse and violence in teenage relationships. British Journal of Social Work, 39, 211-233.

Bell, D. (1983). Daughters of the dreaming George. Sydney: Allen and Unwin. 
Bolger, A. (1991). Aboriginal women and violence: A report for the Criminology Research Council and the Northern Territory Commissioner of Police. Darwin: Australian National University North Australia Research Unit.

Burbank, V. K. (1994). Fighting women: Anger and aggression in aboriginal Australia. Berkeley, CA: University of California Press.

Chenhall, R., Davison, D., Fitz, J., Pearse, T., \& Senior, K. (2013). Engaging youth in sexual health research: Refining a 'youth friendly' method in the northern territory, Australia. Visual Anthropology Review, 29(2), 123-132.

Chung, D. (2005). Violence, control, romance and gender equality: Young women and heterosexual relationships. Woman's Studies International Forum, 28, 445-455.

Dublin Women's Aid. (1999). Teenage tolerance: The hidden lives of young Irish people. A study of young people's experience and responses to violence and abuse. Dublin, $\mathrm{OH}$ : Women's Aid.

Goodale, J. C. (1971). Tiwi wives: A study of the women of Melville Island, North Australia. Seattle: University of Washington Press.

Jackson, S. M., \& Cram, F. (2003). Disrupting the sexual double standard: Young woman's talk about heterosexuality. British Journal of Social Psychology, 42, 113-127.

Kelly, L. (1987). The continuum of sexual violence. In J. Hanmer \& M. Maynard (Eds.), Women, violence and social control (pp. 46-60). London: Macmillan Press.

Kenway, J. \& Fitzclarence, L. (1997). Masculinity, violence and schooling: Challenging 'poisonous pedagogies. Gender and Education, 9(1), 117-134.

Hiatt, L. R. (1965). Kinship and conflict: A study of an aboriginal community in northern Arnhem Land. Canberra: Australian National University Press.

Langton, M. (1994). Medicine square. In I. Keen (Ed.), Being black, aboriginal cultures in 'settled' Australia (pp. 201-225). Canberra: Aboriginal Studies Press.

Lavoie, F., Robitaille, L., \& Herbert, M. (2000). Teen dating relationships and aggression an exploratory study. Violence against women, 6(1), 6-36.

Lees, S. (1993). Sugar and spice: Sexuality and adolescent girls. London: Penguin Books.

Macdonald, G. (1994). A Wiradjuri fight story. In I. Keen (Ed.), Being black, aboriginal cultures in 'settled' Australia (pp. 179-199). Canberra: Aboriginal Studies Press.

McCarry, M. (2007). Masculinity studies and male violence: Critique or collusion. Women's Studies International Forum, 30(5), 404-415.

Merskin, D. (2011). A boyfriend to die for: Edward Cullen as compensated psychopath in Stephanie Meyer's Twilight. Journal of Communication Inquiry, 35(2), 157-178.

Powell, A. (2007). Youth at risk? Young people, sexual health and consent. Youth Studies Australia, 26(4), 21-28.

Powell, A. (2010). Sex, power and consent, youth culture and the unwritten rules. Melbourne: Cambridge University Press.

Power, R., Langhaug, L., \& Cowan, F. (2007). 'But there are no snakes in the wood': Risk mapping as an outcome measure in evaluating complex interventions. Sexually Transmitted Infections, 82, 232-236.

Rasmussen, M. L. (2015). Sex education, bodily orientation and the Northern Territory Intervention. In S. R. Poyntz \& J. Kennelly (Eds.), Phenomenology of youth cultures and globalization: Life worlds and surplus meaning in changing times (pp. 183-212). Abingdon: Taylor and Francis.

Renold, R., \& Ringrose, J. (2011). Schizoid subjectivities? Re-theorizing teen girls' sexual cultures in an era of 'sexualization'. Journal of Sociology, 47(4), 389-409.

Rosen, D. (2004). 'I just let him have his way': Partner violence in the lives of low-income, teenage mothers. Violence Against Women, 10(1), 6-28.

Scott, M. E., Steward-Streng, N. R., Manlove, J., Schelar, E., \& Cui, C. (2011). Characteristics of young adult sexual relationships, sometimes violent, often loving. Bethesda, WI: Childtrends.

Senior, K. (2003). A Gudbala Laif? Health and well-being in a remote Aboriginal - what are the problems and where lies responsibility? (Unpublished doctoral dissertation).Australian National University, Canberra. 
Senior, K., \& Chenhall, R. D. (2008). 'Walkin' about at night: The background to teenage pregnancy in a remote Aboriginal community. Journal of Youth Studies, 11(3), 269-281.

Senior, K., \& Chenhall, R. (2012). Boyfriends and basketball: Present lives and future aspirations of young women in a remote Australian Aboriginal Community. Journal of Youth Studies, 15(3), 369-388.

Senior, K. Helmer, J., \& Chenhall, R. (2014). Young clean and safe? Young people's perceptions of risk from sexually transmitted infections in regional, rural and remote Australia. Culture Health and Sexuality, 16(4), 453-466.

Tolman, D. L. (2002). Dilemmas of desire, teenage girls talk about sexuality. Cambrdige: Harvard University Press.

Vinson, T. (2008). Some lexical variance of Australian Aboriginal English. Griffith Working Papers in Pragmatics and Intercultural Communication, 1(1), 1-6.

Warner, W. L. (1958). A black civilisation: A Study of an Australian Aboriginal Tribe. New York, NY: Harper Books.

Wekerle, C., \&Wolfe, D. A. (1999). Dating violence in mid adolescence: Theory, significance and emerging prevention initiatives. Clinic Psychology Review, 19(4), 435-456. 


\section{University Library}

\section{- M M I N E R VA \\ A gateway to Melbourne's research publications}

Minerva Access is the Institutional Repository of The University of Melbourne

Author/s:

Senior, K;Helmer, J;Chenhall, R

Title:

'As long as he's coming home to me': vulnerability, jealousy and violence in young people's relationships in remote, rural and regional Australia

Date:

2017-01-01

\section{Citation:}

Senior, K., Helmer, J. \& Chenhall, R. (2017). 'As long as he's coming home to me': vulnerability, jealousy and violence in young people's relationships in remote, rural and regional Australia. HEALTH SOCIOLOGY REVIEW, 26 (2), pp.204-218. https:// doi.org/10.1080/14461242.2016.1157697.

Persistent Link:

http://hdl.handle.net/11343/116637 